\title{
Frequency dependence of specific airway resistance in a commercialized plethysmograph
}

\author{
R. Peslin*, C. Duvivier*, P. Malvestio**, A.R. Benis*, J.M. Polu**
}

Frequency dependence of specific airway resistance in a commercialized plethysmograph. R. Peslin, C. Duvivier, P. Malvestio, A.R. Benis, J.M. Polu. @ERS Journals Ltd 1996. ABSTRACT: Specific airway resistance (sRaw) measured by body plethysmography has been shown to decrease markedly with decreasing breathing frequency when the inspired air is not conditioned to body temperature, atmospheric pressure and saturation with water vapour (BTPS). The phenomenon has been attributed to noninstantaneous gas warming and wetting in the airways. The aim of this investigation was to assess whether the phenomenon was also present in a commercialized plethysmograph featuring an "electronic BTPS correction".

Airway resistance $(R$ aw) and $s R$ aw were measured in 15 healthy subjects at six breathing frequencies ranging $0.25-3 \mathrm{~Hz}$, using a constant volume plethysmograph in which a correction for non-BTPS gas conditions was applied by electronically flattening the box pressure-airway flow loop (Jaeger Masterscreen Body, version 4.0).

The temperature and water vapour saturations in the box averaged $26.5 \pm 1.3^{\circ} \mathrm{C}$ and $59 \pm 6 \%$, respectively. $R$ aw and $\mathrm{R}$ aw exhibited a clear positive frequency dependence in all but one subject. From 0.25 to $3 \mathrm{~Hz} R$ aw increased from (mean \pm SD) $0.62 \pm 0.55$ to $1.71 \pm+0.76 \mathrm{hPa} \cdot \mathrm{s} \cdot \mathrm{L}^{-1}(\mathrm{p}<0.001)$, and $\mathrm{s} R$ aw from $2.34 \pm 1.90$ to $7.55 \pm 3.08$ hPa's $(\mathrm{p}<0.001)$. The data are consistent with a simple model, in which gas conditioning in the airways and external dead space occurred with a time constant of $0.39 \mathrm{~s}$.

We conclude that the electronic BTPS correction of the instrument was inadequate, probably because it is assumed that gas conditioning in the airways is instantaneous. We recommend that, with similar instruments, airway resistance be measured using as high a panting frequency as feasible.

Eur Respir J., 1996, 9, 1747-1750.
*Unité 14 de Physiopathologie Respiratoire, Institut National de la Santé et de la Recherche Médicale, Université Henri Poincaré, Nancy, France. **Service des Maladies Respiratoires, CHRU Nancy-Brabois, Vandoeuvre-lesNancy, France.

Correspondence: R. Peslin

Unité 14 INSERM

Physiopathologie Respiratoire

C.O.n ${ }^{\circ} 10$

54511 Vandoeuvre-les-Nancy cedex

France

Keywords: Body plethysmography gas conditioning respiratory mechanics thermal artifact

Received: October 131995

Accepted after revision March 161996
When a subject breathes ambient air inside a body plethysmograph, the largest part of the volume variations measured by the instrument $(V \mathrm{pl})$ is due to the warming and humidification of inspired air in the airway during the inspiratory phase and to its partial cooling during the expiratory phase. Computed according to the equation of Drorbaugh and FenN [1] the change in $V \mathrm{pl}$ occurring when a tidal volume of $0.6 \mathrm{~L}$ at $22^{\circ} \mathrm{C}$ and $50 \%$ water vapour saturation $\left(\mathrm{SH}_{2} \mathrm{O}\right)$ is conditioned to body temperature, atmospheric pressure and saturation with water vapour (BTPS) amounts to about $57 \mathrm{~mL}$. This thermal component of $V \mathrm{pl}$ is more than 10 times larger than the airway resistance ( $R$ aw) component expected in a normal subject (specific $R$ aw $(\mathrm{s} R \mathrm{aw}=5 \mathrm{hPa} \cdot \mathrm{s})$ ) at a flow rate of 1 $\mathrm{L} \cdot \mathrm{S}^{-1}$.

Accurate measurements of $s R$ aw by body plethysmography, therefore, requires eliminating as completely as possible the thermal component of $V \mathrm{pl}$. The method of choice consists in having the subject rebreathe from a bag or a bellows a gas conditioned to BTPS [2-4]. Until recently, the method was implemented in several commercialized plethysmographs (e.g. Fenyves and Gut, Basel; Jaeger, Würsburg), but it seems to be rarely used nowadays, probably because a gas conditioner increases the cost of the instrument and also for considerations of hygiene.

An alternative is to have the subject pant through the instrumental deadspace [5]. Indeed, panting increases the ratio of the Raw component (which is proportional to the flow amplitude) to the thermal component (which is proportional to the tidal volume). Moreover, it has been suggested that the change in gas temperature is minimized during shallow breathing if the front between plethysmograph air and pulmonary air remains inside the heated flowmeter [5].

A third method is based on the assumption that the change in gas condition is instantaneous and, consequently, is strictly in phase with inspired and expired volume $(V)$, in contrast with the resistive component which is in phase with flow $\left(V^{\prime}\right)$. The thermal component may then be eliminated by subtracting from $V$ pl a signal proportional to $V$ with the appropriate amplitude (subtraction method [6-8]); the method is equivalent to extracting the component of $V \mathrm{pl}$ which is in phase with flow, and using it to compute sRaw.

In a recent study [9], we have observed that, when breathing unconditioned air, the apparent $\mathrm{s} R \mathrm{aw}$, computed from the component of $V \mathrm{pl}$ in phase with flow, decreased 
markedly with decreasing breathing frequency; as a result, $s R$ aw was strongly underestimated in healthy subjects at panting frequencies below $2 \mathrm{~Hz}$. The phenomenon was clearly related to the temperature of the inspired air, and could be explained by noninstantaneous gas conditioning in the airways. The data were consistent with a time constant for heat and water vapour exchanges of about 100 $\mathrm{ms}$. As these observations were performed using a homemade plethysmograph and by computing the in-phase component of $V \mathrm{pl}$ by Fourier analysis, the aim of the present investigation was to assess whether the phenomenon was also present with a commercialized plethysmograph, in which the above-mentioned subtraction method is used to deal with the thermal component.

\section{Methods}

The study was performed in 15 healthy subjects recruited among people working in the laboratory and the nearby hospital. Their biometric characteristics are listed in table 1, along with their thoracic gas volume (TGV).

All measurements were made in an $830 \mathrm{~L}$ constant volume body plethysmograph (Jaeger Masterscreen Body, version 4.0, Würzburg, Germany). The instrument did not have a heated rebreathing bag as did previous models from the same firm, but featured electronic BTPS correction to eliminate the thermal component of $V \mathrm{pl}$ (Automatischer Schleifen-Computer or ASC compensation). The compensation is normally set in such a way as to completely flatten the $V \mathrm{pl}-V^{\prime}$ loops in healthy subjects. The plethysmograph was calibrated using the builtin $50 \mathrm{~mL}$ calibration pump. The system also allowed checking of the box leakage time constant, which was always close to $10 \mathrm{~s}$ ( $7 \mathrm{~s}$ half-life). The screen-type pneumotachograph was calibrated daily with a $2 \mathrm{~L}$ syringe.

Resistance measurements were performed at six different frequencies $(0.25,0.5,0.75,1,2$ and $3 \mathrm{~Hz})$ in random order. To help the subject achieve the required respiratory rate, a sinusoidal signal was displayed in front of him on an oscilloscope. At each frequency the signals were recorded until five satisfactory $V \mathrm{pl}-V^{\prime}$ loops were obtained, after which the shutter was closed for $4 \mathrm{~s}$ to measure TGV. The temperature (T) and $\mathrm{SH}_{2} \mathrm{O}$ in the plethysmograph were also measured in front of the subject, at 30-40 cm from the mouthpiece-shutter assembly (Testotherm, Testo 610, Forbach, France). The door of the plethysmograph was open after each measurement to avoid a progressive increase in box temperature.

The results were drawn from the "best" $V \mathrm{pl}-V^{\prime}$ loop, as automatically selected by the system software (curve whose result is closest to the mean). If necessary, the ASC compensation was adjusted to abolish any residual looping between $V \mathrm{pl}$ and $V^{\prime}$. Among various possibilities offered by the instrument, we chose to compute $R$ aw and sRaw by the integral method or "effective" resistance method [10], which minimizes the influence of the noise. With that method, sRaw and $R$ aw are derived from the ratio of the area of the $V \mathrm{pl}-V$ loop (proportional to mechanical work) to the area of the $V^{\prime}-V$ loop. In nine out of 15 subjects, the measurements were made in duplicate, and the mean of the two series was taken at each frequency. In one subject, no data could be obtained at the lowest frequency because the system automatically rejected any negative resistance value. In that instance, the apparent resistance was taken as being zero.

The influence of panting frequency on the data was assessed using one-way analysis of variance.

\section{Results}

As the measurements were made during the summer, box temperatures were high, ranging $24.7-28.9^{\circ} \mathrm{C}$ (table $1)$. In a given subject, $\mathrm{T}$ varied little during the entire session (mean standard deviation of $0.22^{\circ} \mathrm{C}$ ). The water vapour saturations were more variable, both between individuals (ranging 50.1-70.1, table 1), and within individuals (mean standard deviation of $2.4 \%$ ). Variance analysis did not show any significant variation of $\mathrm{T}$ and $\mathrm{SH}_{2} \mathrm{O}$ according to the panting frequency.

Specific resistance data in representative subjects are shown in figure $1 \mathrm{a}$, and the mean values of $R$ aw and $\mathrm{s} R \mathrm{aw}$ in the group are shown in figure $1 \mathrm{~b}$. The variations of resistance with frequency were somewhat irregular (Fig. 1a) but $R$ aw and $\mathrm{s}$ aw exhibited a clear positive frequency

Table 1. - Biometric characteristics, thoracic gas volumes and gas conditions in the plethysmograph

\begin{tabular}{|c|c|c|c|c|c|c|c|}
\hline $\begin{array}{c}\text { Subject } \\
\text { No. }\end{array}$ & Sex & $\begin{array}{l}\text { Age } \\
\text { yrs }\end{array}$ & $\begin{array}{c}\text { Height } \\
\mathrm{cm}\end{array}$ & $\begin{array}{c}\text { Weight } \\
\text { kg }\end{array}$ & $\begin{array}{c}\mathrm{TGV} \\
\mathrm{L}\end{array}$ & ${ }^{\circ} \mathrm{C}$ & $\underset{\%}{\mathrm{SH}_{2} \mathrm{O}}$ \\
\hline 1 & M & 33 & 173 & 69 & 4.2 & 28.1 & 62 \\
\hline 2 & $\mathrm{M}$ & 27 & 179 & 71 & 4.4 & 24.7 & 57 \\
\hline 3 & $\mathrm{~F}$ & 33 & 171 & 70 & 3.9 & 27.8 & 67 \\
\hline 4 & $\mathrm{M}$ & 56 & 168 & 66 & 4.1 & 25.4 & 55 \\
\hline 5 & $\mathrm{~F}$ & 35 & 170 & 60 & 4.1 & 28.3 & 68 \\
\hline 6 & $\mathrm{M}$ & 57 & 178 & 56 & 6.0 & 28.9 & 54 \\
\hline 7 & M & 46 & 182 & 80 & 5.0 & 26.4 & 63 \\
\hline 8 & $\mathrm{~F}$ & 50 & 157 & 55 & 4.0 & 26.0 & 59 \\
\hline 9 & $\mathrm{~F}$ & 47 & 170 & 61 & 4.7 & 26.3 & 62 \\
\hline 10 & $\mathrm{M}$ & 28 & 187 & 87 & 5.7 & 27.0 & 63 \\
\hline 11 & $\mathrm{M}$ & 49 & 168 & 90 & 3.6 & 25.2 & 70 \\
\hline 12 & $\mathrm{~F}$ & 62 & 158 & 54 & 3.4 & 26.5 & 59 \\
\hline 13 & $\mathrm{~F}$ & 39 & 160 & 60 & 3.6 & 25.3 & 51 \\
\hline 14 & $\mathrm{~F}$ & 38 & 155 & 48 & 3.7 & 25.5 & 51 \\
\hline 15 & M & 46 & 174 & 75 & 3.8 & 25.8 & 50 \\
\hline
\end{tabular}

M: male; F: female. TGV: thoracic gas volume; $\mathrm{T}$ : temperature in the plethysmograph; $\mathrm{SH}_{2} \mathrm{O}$ : water vapour saturation in the plethysmograph. TGV, T and $\mathrm{SH}_{2} \mathrm{O}$ are the means of the values obtained during the various manoeuvres. 
a)

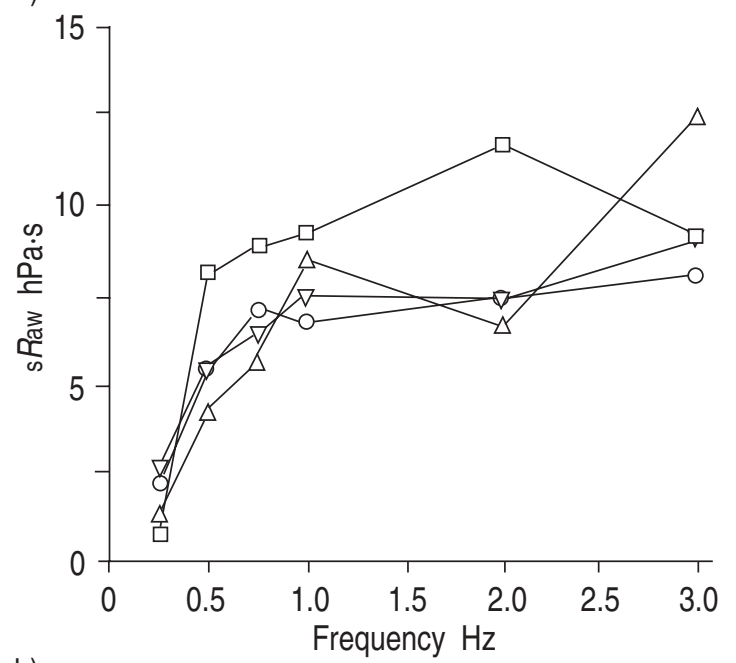

b)

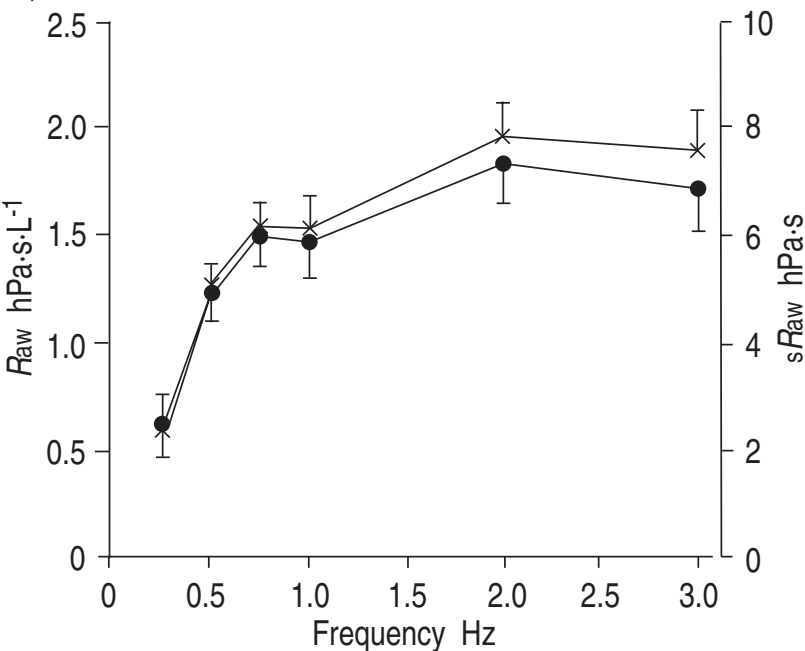

Fig. 1. - Variations of airway resistance (Raw) and specific airway resistance (sRaw) as a function of the panting frequency. a) sRaw data in 4 representative subjects (Nos. 7-10); means of duplicate measurements. b) Means and standard errors in the group. - - Raw ; $\longrightarrow$ : sRaw.

dependence in all but one subject. From 0.25 to $3 \mathrm{~Hz}$, $R$ aw (mean $\pm \mathrm{SD}$ ) increased on average from $0.62 \pm 0.55$ to $1.71 \pm 0.76 \mathrm{hPa} \cdot \mathrm{s} \cdot \mathrm{L}^{-1}$, and $\mathrm{s} R$ aw from $2.34 \pm 1.90$ to $7.55 \pm 3.08$ $\mathrm{hPa} \cdot \mathrm{s}$. The trend was highly significant $(\mathrm{p}<0.001$ for both indices).

\section{Discussion}

In the frequency range explored in this study, human lung resistance, obtained from transpulmonary pressure measurements, has been found to decrease slightly with increasing frequency, a feature attributed to tissue viscoelasticity $[11,12]$. It is, therefore, very unlikely that $R$ aw actually exhibits a strong positive frequency dependence. Indeed, when measured by plethysmography with the subject breathing air saturated with water vapour and warmed at $34-40^{\circ} \mathrm{C}$, sR aw increases only moderately between 0.5 to $3 \mathrm{~Hz}$ [9]. This increase probably reflects the net effect of the flow dependence of Raw [13] and of the variations in the glottis opening with increasing frequency $[5,14]$.
The marked frequency dependence of $R$ aw and $s R$ aw observed in this study is qualitatively in agreement with our previous observations. This agreement is not surprising, since the electronic correction performed in the instrument to deal with the thermal component of $V$ pl flattens the $V \mathrm{pl}-V$ loops but, presumably, does not modify its slope. We had previously found in six healthy subjects that the real part of the $V \mathrm{pl}-V^{\prime}$ relationship (sRaw/ (PB$P_{\mathrm{H}_{2}} \mathrm{O}$ ) with $P \mathrm{~B}$ the barometric pressure) increased by $4.01 \pm$ $1.24 \mathrm{~ms}$ from 0.5 to $3 \mathrm{~Hz}$. The corresponding figure in terms of $\mathrm{s} R$ aw is $3.72 \pm 1.16 \mathrm{hPa} \cdot \mathrm{s}$, to be compared to an increase by $2.53 \pm 2.45 \mathrm{hPa} \cdot \mathrm{s}$ on the same frequency range in this study. The smaller variation observed here is consistent with the higher gas temperature in the plethysmograph $\left(26.5 \pm 1.3^{\circ} \mathrm{C}\right.$ compared to $\left.19.2 \pm 0.8^{\circ} \mathrm{C}\right)$.

Indeed, the frequency dependence of $s R$ aw may be explained by a simple model [9], in which the change in gas temperature and $\mathrm{PH}_{2} \mathrm{O}$ from box to alveolar conditions is not instantaneous, but occurs with some time constant $(\theta)$. Then, some of the thermal component of $V \mathrm{pl}$ is outof-phase with volume, and contaminates what is taken to be the resistive term. The model predicts that for sinusoidal breathing, the apparent $\mathrm{s} R$ aw (sRaw,a) will vary with frequency according to:

$$
\mathrm{s} R \mathrm{aw}, \mathrm{a}=\mathrm{s} R \mathrm{aw}-\theta \cdot \mathrm{G} \cdot\left(P \mathrm{~B}-P \mathrm{H}_{2} \mathrm{O}\right) /\left(1+\theta^{2} \omega^{2}\right)
$$

where $\omega=2 . \pi$. $f$ and where $\mathrm{G}$ depends on the absolute temperatures (t) and $\mathrm{PH}_{2} \mathrm{O}$ of the inspired (index i) and alveolar (index A) gas [1]:

$$
\mathrm{G}=1-(t \mathrm{i} / t \mathrm{~A}) \cdot\left(P \mathrm{~B}-P \mathrm{H}_{2} \mathrm{O}, \mathrm{A}\right) /\left(P \mathrm{~B}-P \mathrm{H}_{2} \mathrm{O}, \mathrm{i}\right)
$$

In practice $\mathrm{G}$ will be somewhat lower than computed from Equation (2) because the thermal phenomenon is asymmetrical, the change in gas condition in the airway and dead space being less during the expiratory phase than during the inspiratory phase $[9,15]$.

To test if the data in this study were consistent with the model, we have fitted Equation (1) to our mean sRaw values (fig. 1b) using a least squares criterion. As shown in figure 2, the model provided a reasonably good description of the data (root-mean-square error of $0.28 \mathrm{hPa} \cdot \mathrm{s}$ ).

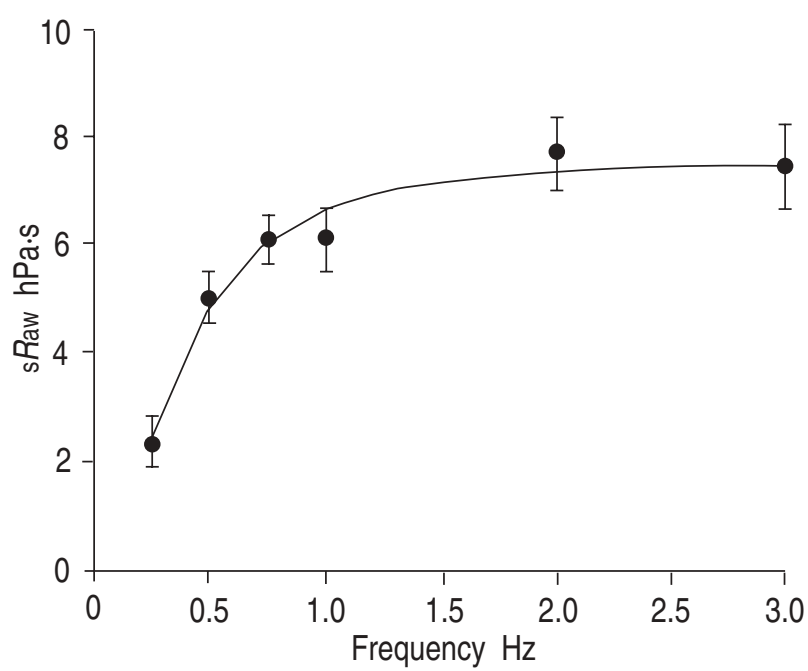

Fig. 2. - Best fit of model (Equation (1)) to mean specific airway resistance ( $\mathrm{s} R$ aw) data. Values are presented as mean \pm SEM $(\mathrm{n}=15)$. $\mathrm{s} R \mathrm{aw}=7.706 \mathrm{hP} \cdot \mathrm{s} ; \theta=0.393 \mathrm{~s} ; \mathrm{G}=0.020$. 
The value of $\mathrm{G}$ giving the best fit (0.020) was, however, lower than expected from our temperature and $\mathrm{SH}_{2} \mathrm{O}$ measurements (about 0.048 assuming that the expired gas cools down to $34^{\circ} \mathrm{C}$ in the dead space). An explanation may be that the temperature and/or $\mathrm{SH}_{2} \mathrm{O}$ of the gas in the box were higher at the extremity of the dead space than at the point where they were measured. Also, the value of $\theta(0.393 \mathrm{~s})$ was substantially higher than in our previous study, where it ranged $0.09-0.19 \mathrm{~s}$, depending on the volume of the instrumental dead space and on the type of pneumotachograph. The very fact that $\theta$ depends upon the geometry of the instrumental dead space (probably its surface/volume ratio) suggests that some of the heat exchange takes place at that level. The larger $\theta$ fitting the data may, therefore, be related to the particular geometry of the dead space, which, beside the pneumotachograph-shutter assembly $(160 \mathrm{~mL})$, included side pathways $(540 \mathrm{~mL})$ designed for other applications of the system. Alternatively, as the temperature differences between the box and the alveoli were much less in this study than in our previous one, the unexpectedly low $\mathrm{G}$ and high $\theta$ may reflect the shortcomings of our simple model. The latter assumes linear behaviour (neglecting, in particular, the flow dependence of resistance), and describes the thermal process with a single time constant.

To summarize our findings, we observed in a commercialized plethysmograph, in which inspired gas was not conditioned to BTPS, and where an electronic correction was applied to deal with thermal volume changes, that the measured $R$ aw and $s R$ aw decreased markedly with decreasing breathing frequency. These data support our previous conclusion $[9,16]$ that the warming and wetting of inspired gas in the airways is not instantaneous and, therefore, is partially in phase with flow, contaminating the resistive component of the box signal. This may result in a substantial underestimation of resistance when the measurements are made at usual breathing frequencies. The problem is likely to be worse when box temperature is lower than in this study. One should note, however, that the absolute error is independent of the value of $s R$ aw, so that the relative error will be less in patients with airway obstruction than in normal subjects.

As we do not know how the thermal component of $V \mathrm{pl}$ is dealt with in other commercialized plethysmographs without gas conditioning, we cannot generalize our conclusions. However, the error is expected to be substantial at spontaneous breathing frequency over a large range of thermal time constants [9] in any plethysmograph where the correction only flattens the $V \mathrm{pl}-V^{\prime}$ loop. One may, therefore, recommend that with such instruments airway resistance be measured using as high a panting frequency as is feasible and compatible with other requirements.

Acknowledgements: The authors are grateful to B. Clement for editing the manuscript and to M.C. Rohrer for the illustrations.

\section{References}

1. Drorbaugh JE, Fenn WO. A barometric method for measuring ventilation in newborn infants. Pediatrics 1955; 16: 81-87.

2. Jaeger, MJ, Bouhuys A. Loop formation in pressure vs flow diagrams obtained by body plethysmographic techniques. In: DuBois AB, van de Woestijne KP, eds. Body Plethysmography. DuBois AB and van de Woestijne KP Eds, Progress in Respiration Research. Vol. 4. Basel, Karger, 1969; pp. 116-130.

3. Jaeger MJ, Otis AB. Measurement of airway resistance with a volume displacement body plethysmograph. $J$ Appl Physiol 1964; 19: 813-820.

4. Jonson B, Bouhuys A. Measurement of alveolar pressure. J Appl Physiol 1967; 22: 1081-1085.

5. DuBois AB, Botelho SY, Comroe JH. A new method for measuring airway resistance in man using a body plethysmograph: values in normal subjects and in patients with respiratory disease. J Clin Invest 1956; 35 : 327-335.

6. Bargeton D, Barrès G, Lefebvre des Noettes R, Gauge P. Résistance des voies aériennes de l'homme au cours du cycle respiratoire. CR Soc Biol 1957; 151: 427-432.

7. Smidt U, Muysers K, Buchheim W. Electronic compensation of differences in temperature and water vapour between inspired and expired air and other signal handling in body plethysmography. In: DuBois AB, van de Woestijne KP, eds, Body Plethysmography. Progress in Respiration Research. Vol. 4. Basel, Karger, 1969; pp. 39-49.

8. Woitowitz HJ, Günthner W, Woitowitz R. Some experience with electronic simulation of BTPS conditions in body plethysmography. In: DuBois AB, van de Woestijne KP, eds, Body Plethysmography. Progress in Respiration Research. Vol. 4. Basel, Karger, 1969; pp. 50-60.

9. Peslin R, Duvivier C, Vassiliou M, Gallina C. Thermal artifacts in plethysmographic airway resistance measurements. J Appl Physiol 1995; 79: 1958-1965.

10. Matthys H, Orth U. Comparative measurements of airway resistance. Respiration 1975; 32: 121-134.

11. Hantos Z, Daroczy B, Suki B, Galgoczy G, Csendes T. Forced oscillation impedance of the respiratory system at low frequencies. J Appl Physiol 1986; 60: 123-132.

12. Farré R, Peslin R, Rotger M, Navajas D. Human lung impedance from spontaneous breathing frequencies to 32 Hz. J Appl Physiol 1994; 76: 1176-1183.

13. Rohrer F. Der Stroemungswiderstand in den menschlichen Atemwegen und der Einfluss der unregelmaessigen Verzweigung des Bronchialsystems auf den Atmungsverlauf in verschiedenen Lungenbezirken. Arch Ges Physiol 1915; 162: 225-300.

14. Stanescu DC, Pattijn J, Clement J, van de Woestijne KP. Glottis opening and airway resistance. J Appl Physiol 1972; 32: 460-466.

15. Epstein MAF, Epstein RA. A theoretical analysis of the barometric method for measurement of tidal volume. Respir Physiol 1978; 32: 105-120.

16. Peslin R, Jardin P, Hannhart B. Modeling of the relationship between volume variations at the mouth and chest. J Appl Physiol 1976; 41: 659-667. 